\title{
Fucoidan prevent murine autoimmune diabetes via suppression TLR4-signaling pathways, regulation DC/Treg induced immune tolerance and improving gut microecology
}

\author{
Meilan Xue ${ }^{1}$, Hui Liang ${ }^{2^{*}}$, Xinqiang $\mathrm{Ji}^{3}$, Ying Liu', Yinlin Ge${ }^{1}$, Lin $\mathrm{Hou}^{1}$ and Ting Sun ${ }^{1}$
}

\begin{abstract}
Background: This study was to investigate the effect and its possible mechanism of fucoidan on the development of spontaneous autoimmune diabetes in non-obese diabetic (NOD) mice.

Methods: 7-week-old NOD mice were randomly divided into three groups: control group, low-dose (300 mg/kg) and high-dose $(600 \mathrm{mg} / \mathrm{kg})$ fucoidan-treatment groups. After 5 weeks of treatment, 10 mice per group were randomly selected to be sacrificed after feces collection. The remaining 12 mice per group were fed until 26 weeks of age to assess the incidence of diabetes.

Results: Treatment with fucoidan increased serum insulin level, delayed the onset and decreased the development of diabetes in NOD mice. Fucoidan reduced the levels of strong Th1 proinflammatory cytokines, but induced Th2bias ed. cytokine response. And dentridic cells (DCs) in fucoidan treatment group were characterized as low expression of MHC class II and CD86 molecules. TLR4 expressions and the downstream molecules in pancreas were down-regulated in fucoidan-treated groups. There were significant differences in the composition of gut flora between NOD control group and fucoidan group. Lactobacillus and Akkermansia were significantly enriched in fucoidan group.
\end{abstract}

Conclusions: Fucoidan could prevent the development of autoimmune diabetes in NOD mice via regulating DC/ Treg induced immune tolerance, improving gut microecology, down-regulating TLR4 signaling pathway, and maintaining pancreatic internal environment.

Keywords: Type 1 diabetes, Non-obese diabetic mice, Fucoidan, Immune tolerance, Gut microecology

\section{Background}

Autoimmune diabetes, also known as Type 1 diabetes mellitus (T1DM), is an autoimmune-mediated disease characterized by selective destruction of insulin-producing pancreatic $\beta$-cell [1]. The pathogenesis of T1DM relates to genetic factors, autoimmune factors and environmental factors. Based on genetic factors and triggered by environmental factors, it is autoimmune disease

\footnotetext{
* Correspondence: lianghuiyxb@163.com

${ }^{2}$ The Institute of Human Nutrition, Qingdao University of Medicine, Qingdao 266021, People's Republic of China

Full list of author information is available at the end of the article
}

characterized by $\mathrm{T}$ lymphocytes-mediated progressive damage of islet B cells.

Studies have confirmed that Toll-like receptors (TLRs) are a key family involved in the development of autoimmune inflammation, and inhibition of TLR signaling pathway has great potential in the treatment of autoimmune diseases [2]. In recent years, the role of TLR4 in T1DM has attracted great attention. TLR4 is the main receptor on beta cells and a key molecule that leads to autoimmune damage of beta cells and can serve as an early marker of damage of beta cells [3, 4]. Clinical studies have also shown that TLR4 expression and ligand levels are 
increased in T1DM patients compared with the control group [5-7]. TLR4 knockout improved the inflammatory state of streptoureasin-induced T1DM model [8].

Regulatory $\mathrm{T}$ cells (Tregs) and dendritic cells (DC) are also involved in the pathogenesis of T1DM and play a key role in controlling the progress of the disease. CD4+ CD25+ Tregs could inhibit the differentiation of islet reactive $\mathrm{CD} 8+\mathrm{T}$ cells into cytotoxic $\mathrm{T}$ lymphocytes and prevent the progress of T1DM $[9,10]$. Rodent experiments and clinical studies have shown that the gradual loss of Treg inhibition ability is closely related to the development of T1DM $[11,12]$. Increasing the differentiation of Treg in NOD mouse model or promoting Treg generation has been proved to be an effective means to combat the occurrence and development of T1DM by protecting beta cells of the pancreas from autoimmune attack. Therapy of type 1 diabetes with CD4(+) CD25 (high) CD127-regulatory $\mathrm{T}$ cells prolonged survival of pancreatic islets [13]. Furthermore, the abnormalities in phenotype, maturation and function of DC are related to defective immune regulation of NOD mice and human T1DM [14]. DC also participates in the maintenance of the autoimmune process of T1DM by presenting its own antigen, and mature $\mathrm{DC}$ can promote the self-reactive $\mathrm{T}$ cell response and reduce the pathogenesis of T1DM [15].

Moreover, as one of environmental factors, gut flora has a direct relationship with the occurrence of type 1 diabetes by changing intestinal permeability and host immune system [16-18]. Under physiological conditions, gut flora acts as a barrier to intestinal microorganisms, but once the intestinal structure changes, intestinal wall permeability will increase, and then the intestinal immune function also change, which will result in impaired immune tolerance. So microorganisms and anomaly antigens can activate the host immune system through the intestinal barrier, leading to local and systemic inflammatory reaction of target organs. Existing reports have shown that the gut microbiota is associated with the pathogenesis of T1DM in human and non-obese diabetic (NOD) mice $[19,20]$. The incidence of T1DM decreased in NOD mice with My88 gene knockout that was given antibiotics to maintain intestinal sterility after intestinal implantation of specific intestinal shade groups, suggesting that gut flora may prevent T1DM. Gut microbial metabolites limit the frequency of autoimmune $\mathrm{T}$ cells and protect against type 1 diabetes [21].

Fucoidan, a complex sulfated polysaccharide obtained from brown seaweed, has been widely investigated for its antioxidant, anticancer and anti-inflammatory effects $[22,23]$. In vitro and in vivo experiments indicate that fucoidan attenuates hyperglycemia and prevents or impedes the development of diabetic nephropathy related to spontaneous diabetes by attenuating the activation of the NF- $\kappa B$ signaling pathway [24]. Fucoidan can alleviate the inflammatory reaction of P-selection and inflammatory factor, which play a protective role on kidney function of diabetic rats [25]. Recently, fucoidan has been proposed as a potential prebiotic agent for functional food and pharmaceutical development. Shi H, et al. [26] found that dietary fucoidan altered gut flora and repaired the intestinal mucosal injury induced by cyclophosphamide. It is also reported that fucoidan could maintain a more balanced composition of gut flora and reduced the antigen load and the inflammatory response in the host [27]. Our previous studies have examined the effect of fucoidan on intestinal flora and intestinal barrier function in rats with breast cancer. The data showed that dietary supplement of fucoidan could improve the fecal microbiota composition and repair the intestinal barrier function [28]. However, to date and to the best of our knowledge, pathological studies on the effects of fucoidan against autoimmune diabetes in NOD mice have not been carried out.

Fucoidan may regulate intestinal flora and play an effective protective role in T1DM by affecting Treg differentiation and DC phenotype. We attempted to elucidate the molecular mechanism of the protective effect of fucoidan from the perspective of TLR4 signaling pathway. Therefore, NOD mice were used as model animals to conduct in vivo experiments to observe the effect of fucoidan on the pathogenesis of autoimmune diabetes mellitus, and to explore its cellular and molecular mechanisms.

\section{Methods}

\section{Animals and experimental design}

The experiments were carried out according to the $\mathrm{Na}$ tional Institutes of Health Guide for Care and Use of Laboratory Animals (Publication No. 85-23, revised 1985). Animal care and the protocols were in accordance with the Animal Experiment Guidelines of Qingdao University of Medicine and ethical approval was obtained from Qingdao University of Medicine.

Male NOD mice at 6 weeks-old were obtained from Beijing Vital River Laboratory Animal Technology Co., Ltd. (Beijing, China). The mice were housed in a controlled environment at a set temperature $\left(22-25^{\circ} \mathrm{C}\right)$ and humidity $(50-60 \%)$ and under a 12-h light: dark lighting cycle. All mice were allowed 1 week for acclimatization before experimentation and were allowed free access to standard rodent chow and water throughout the study.

At 7 weeks of age, the animals were randomly divided into three groups: control group, low-dose and high-dose fucoidan-treatment groups. The NOD mice in low-dose and high-dose fucoidan-treatment groups were then given with $300 \mathrm{mg} / \mathrm{kg}$. BW (body weight) or $600 \mathrm{mg} / \mathrm{kg} . \mathrm{BW}$ fucoidan from Fucus vesiculosus (Sigma, St. Louis, MO, USA) respectively by intragastric (i.g.) administration 
every day. The fucoidan was dissolved in normal saline. The NOD mice in control group were administrated with $0.1 \mathrm{~mL}$ normal saline via i.g. per day.

The formula of fucoidan is $\mathrm{C}_{18} \mathrm{H}_{27} \mathrm{O}_{21} \mathrm{~S}_{3}$--- and its molecular weight is $675.6 \mathrm{KD}$. As regards the isolation procedure followed by the manufacturer, fucoidans are acid soluble and can be isolated from an algal biomass by simple extraction or by enzymatic digestion. When fucoidan is in solution, it is precipitated with organic solvents using the method described by Black et al. [29]. It is a highly sulphated L-fucose polymer with $95 \%$ purity.

After 5 weeks of treatment, 10 mice at 12-weeks of age per group were randomly selected to perform intraperitoneal glucose tolerance test, and then to be sacrificed after feces collection. Blood, spleen and pancreas were collected. One portion of pancreas tissue was kept in formalin solution $(10 \%)$ for histological examination. The remaining $\mathrm{s}$ pancreas tissue was stored immediately at $-80^{\circ} \mathrm{C}$ for molecular analysis. One Part of each spleen was used to detect cytokine levels, and the other part of spleen tissue was used to detect CD4 + CD25 + Foxp3+ Treg cells. DC cells were isolated from bone marrow and cultured for 7 days, and then their phenotypes were determined.

The remaining 12 mice per group were fed without fucoidan or saline administration until 26 weeks of age, and the tail vein blood was taken twice a week to assess the incidence of diabetes.

\section{Intraperitoneal glucose tolerance test (IPGTT)}

Mice were given $2 \mathrm{~g} / \mathrm{kg}$ glucose $(200 \mathrm{mg} / \mathrm{mL}$ glucose solution) intraperitoneally after fasting for $8 \mathrm{~h}$ at night. Blood samples were collected from the caudal vein before $(0 \mathrm{~h}), 0.5 \mathrm{~h}, 1 \mathrm{~h}, 2$ $\mathrm{h}$ and $3 \mathrm{~h}$ after the injection, respectively, to determine the blood glucose level. The blood glucose levels were determined using Accu-Chek Performa Blood Glucose Monitor Diabetes Meter and blood glucose test strips (Shanghai Roche Testing Products co. LTD, Shanghai, China).

\section{Determination of serum insulin, LPS and Th1/Th2 cytokines in spleen}

The levels of serum insulin were assessed by ELISA using commercial kits (Cloud-Clone Corp, Houston, USA) according to the manufacturer's instructions.

The chromogenic end-point Tachypleus amebocyte lysate (CE TAL) assay kit was used to detecte the level of lipopolysaccharide (LPS) in serum and was purchased from Limulus Reagent Rlant Corp (Xiamen, China). The blood was collected in sterile, endotoxin-free tubes. All containers had pyrogen removed by incubating at $180^{\circ} \mathrm{C}$ for $24 \mathrm{~h}$. The experiment was conducted in accordance with the manufacturer's instructions. Finally, the OD was read at $405 \mathrm{~nm}$. The level of LPS was reported in endotoxin units (EU) per milliliter for serum.
ELISA assay was used to detect the levels of spleen cytokines, including IL-1, IL-2, IL-4, IL-6, IL-10, interferon (IFN) $-\gamma$ and transforming growth factor (TGF) $-\beta$. The experiments were performed according to the manufacturer's protocol (Cloud-Clone Corp, USA).

\section{CD4 + CD25 + Foxp3+ Tregs analysis}

Mouse CD4 + CD25+ Foxp3+ Treg Cells Kit were purchased from eBioscience (San Diego, CA, USA). After the mice were sacrificed, their spleens were quickly removed under aseptic conditions, and part of the spleen tissue was taken to prepare splenic lymphocytes. The spleen tissue was placed in a petri dish containing about $5 \mathrm{~mL}$ of serum RPMI-1640 medium (HyClone, Logan, UT, USA), and the spleen was lightly twisted with a sterile needle core to be a single cell suspension. After 100 mesh nylon mesh filtration, the cell suspension under the mesh was collected in the centrifuge tube. After washed with PBS for three times, the cells were adjusted at $106 / \mathrm{ml}$ concentration.

The cells were incubated with $0.25 \mu \mathrm{L}$ FITC-conjugated anti-mouse CD4 and $0.3 \mu \mathrm{L}$ PE-cy5-conjugated anti-mouse $\mathrm{CD} 25$ at room temperature in the dark for $30 \mathrm{~min}$. After washed with flow cytometry staining buffer twice, the cells were permeabilized with fixation/permeabilization solution in the dark for another $30 \mathrm{~min}$ and then washed twice with flow cytometry staining buffer. Finally, the cells were stained with $0.5 \mu \mathrm{L}$ PE-conjugated anti-mouse Foxp3 prior to analysis using a flow cytometer (Becton Dickinson, Franklin Lakes, NJ, USA) to quantify Tregs frequncies. A door was set on $\mathrm{CD} 4$, with Foxp3 as the abscissa and CD25 as the ordinate.

\section{DC isolation and phenotype identification}

Bone marrow cells were isolated from femurs and tibiae and cultured for 7 days at a density of $1.5 \times 10^{6} / \mathrm{mL}$ in RPMI medium containing 10\% fetal bovine serum (FBS, Gibco, Carlsbad, California, USA), 20 ng/mL rmGM-CSF (Miltenyi Biotech, Bergisch Gladbach, Germany) and10ng/mL rmIL-4 (Miltenyi Biotech, Bergisch Gladbach, Germany) at $37^{\circ} \mathrm{C}$ in a humidified atmosphere with $5 \% \mathrm{CO}_{2}$. After 3 day of culture, half of the medium was exchanged for fresh medium containing $20 \mathrm{ng} / \mathrm{L}$ rmGM-CSF and $10 \mathrm{ng} / \mathrm{mL}$ rmIL-4. On day 7 , cells were collected and the DC phenotype was determined by flow cytometry. FITC-labeled mouse CD11c antibody, PElabeled mouse CD86 antibody, and PE-cy5-labeled mouse MHC-II-antibody were added into the $200 \mu \mathrm{L}$ cell suspension $\left(10^{6} / \mathrm{mL}\right)$, respectively, and incubated in the dark for $30 \mathrm{~min}$. After washed twice with PBS, the cells were resuspended in $400 \mu \mathrm{L}$ PBS. Phenotype of DC was detected on the flow cytometry. A door was set on $\mathrm{CD} 11 \mathrm{c}$, with CD86 as the X-coordinate and MHC class as the Y-coordinate. 


\section{Western blot analysis}

Proteins were extracted from pancreatic tissue by membranal and cytoplasmic Protein Extraction Kit and nuclear and cytoplasmic Protein Extraction Kit (Beyotime Institute of Biotechnology, Jiangsu, China) according to the manufacturer's instructions. BCA Protein Assay Kit (Beyotime Institute of Biotechnology, Jiangsu, China) was used to determine the protein content. Equal amounts of protein were separated on 5\% stacking, 10\% SDS-polyacrylamide gels, and subsequently electrotransferred onto PVDF membrane (Solarbio Science \& Technology, Beijing, China) at $90 \mathrm{~V}$ for $35 \mathrm{~min}$. The membrane was then blocked with $5 \%$ non-fat milk, and incubated with specific primary antibodies overnight at $4{ }^{\circ} \mathrm{C}$.

Samples of cell membrane proteins were used to detect the expression of TLR4. Na, K ATP-ase was used as a reference for determination. Samples of cell plasma protein were used to detected the expression levels of myeloid differentiation factor (MyD)88, interleukin (IL)-1 $\beta$, Toll-IL-1 receptor domain-containing adaptor inducing interferon- $\beta$ (TRIF), interferon (IFN)- $\beta$, LC3 B, p-AMPK, p-mTOR1 inhibition and transcription factor EB (TFEB). $\beta$-actin was used as a reference. The nuclear protein samples were used to detect the expression levels of nuclear factor (NF)$\kappa B$ p65 and interferon regulatory factor (IRF)-3. Histone H3 was used as a reference for nucleoprotein determination. The antibodies for NF-kB p65, IL-1 $\beta, \mathrm{LC} 3 \mathrm{~B}$ and insulin were purchased from Cell Signaling Technology in Danvers, MA, USA. The other antibodies were purchased from Proteintech in Rosemont, IL, USA.

After washing with Tris-buffered saline (TBS) for 10 min three times, the membranes were incubated with corresponding secondary antibody (Zhongshan Goldenbridge Biotechnology, Beijing, China, diluted 1/1000) for $1 \mathrm{~h}$. The membranes were washed and detection was carried out with an ECL Western blotting kit (Pierce, Rockford, IL, USA) according to the manufacturer's instructions.

\section{Immunofluorescence assay}

After dewaxed into water, the pancreatic tissue section was placed in the restoration solution, repaired under high pressure for $5 \mathrm{~min}$, and slowly cooled to room temperature. Then $3 \%$ peroxide was added and the sections were incubated at room temperature for $20 \mathrm{~min}$. After blocked in 1\% BSA for $1 \mathrm{~h}$, the sections were incubated overnight with primary antibody (insulin, NF- $\mathrm{KB}$ p65 and IRF-3) at 1: 60 dilutions. The sections were washed with PBS for 3 times, and incubated with fluorescent second antibody (1: 60) at $37^{\circ} \mathrm{C}$ avoid light for $30 \mathrm{~min}$. The DAPI dyeing solution was stained at room temperature for $20 \mathrm{~min}$. After sealed with water-soluble tablet sealing liquid, the sections were observed and photographed by fluorescence microscope.
Fecal DNA extraction and 16S rDNA gene sequencing

The 16S rDNA gene high-throughput sequencing procedure was performed at the Realbio Genomics Institute (Shanghai, China) by using the Illumina HiSeq platform. The fecal microbiome for 19 fecal samples collected from 9 mice in control group, 10 mice in $600 \mathrm{mg} / \mathrm{kg}$.BW fucoidan treatment group were examined using the Illumina HiSeq 250 platform as described previously [30]. Briefly, the total genomic DNA was extracted from frozen feces using QIAamp DNA Stool Mini Kit (Qiagen, Hilden, Germany) according to the manufacturer's protocol. The $16 \mathrm{~S}$ V3-V4 region was amplified using the primers F341 (CCTACGGGRSGCAGCAG) and R806 (GGAC TACVVGGGTATCTAATC). The raw data were then subjected to a quality control procedure using UPARSE. USEARCH was used to filter chimeras and the remaining sequences were clustered to generate operational taxonomic units (OTUs) at the $97 \%$ similarity level. A representative sequence of each OTU was assigned to a taxonomic level in the RDP database using the RDP classifier. To eliminate the differences caused by variations in the sequencing depth among samples, the least number of sequences obtained were picked randomly for each sample and used for subsequent bioinformatics analysis.

\section{Statistical analysis}

Variance analyses were performed by ANOVA with Tukey's post hoc test. $t$ test was used for comparison the differences between the two groups. Principal components analysis and heat map analysis were conducted with R3.1.0 Differences with $P$ values $<0.05$ were considered significant.

\section{Results}

Effects of fucoidan on glucose tolerance, the incidence of diabetes, serum insulin and LPS levels in NOD mice

The glucose tolerance was determined in mice at 12 weeks of age. As shown in Fig. 1a, compared with the NOD control group, fucoidan treatment $(300 \mathrm{mg} / \mathrm{kg} . \mathrm{BW}$ or $600 \mathrm{mg} / \mathrm{kg} . \mathrm{BW}$ ) significantly lowered blood glucose levels at $30 \mathrm{~min}$ and $60 \mathrm{~min}$ after glucose load $(P<0.05)$. The results showed that glucose tolerance was significantly increased.

After the intervention, blood glucose was measured twice a week until the animal was 26 weeks old. Among the 12 animals observed in each group, 10 mice in the control group developed diabetes (the incidence rate is $83.3 \%$ ). Six mice in low-dose fucoidan group developed diabetes (the incidence rate is 50\%); Only 4 mice in high-dose fucoidan group developed diabetes (the incidence rate is $33.3 \%$ ). It suggests that fucoidan could prevent or delay the development of diabetes in NOD mice (Fig. $1 \mathrm{~b}, P<0.05$ ).

Compared with NOD control mice, serum insulin levels in 12-week-old NOD mice was increased in fucoidan groups (Fig. 1c). After fucoidan intervention LPS levels 


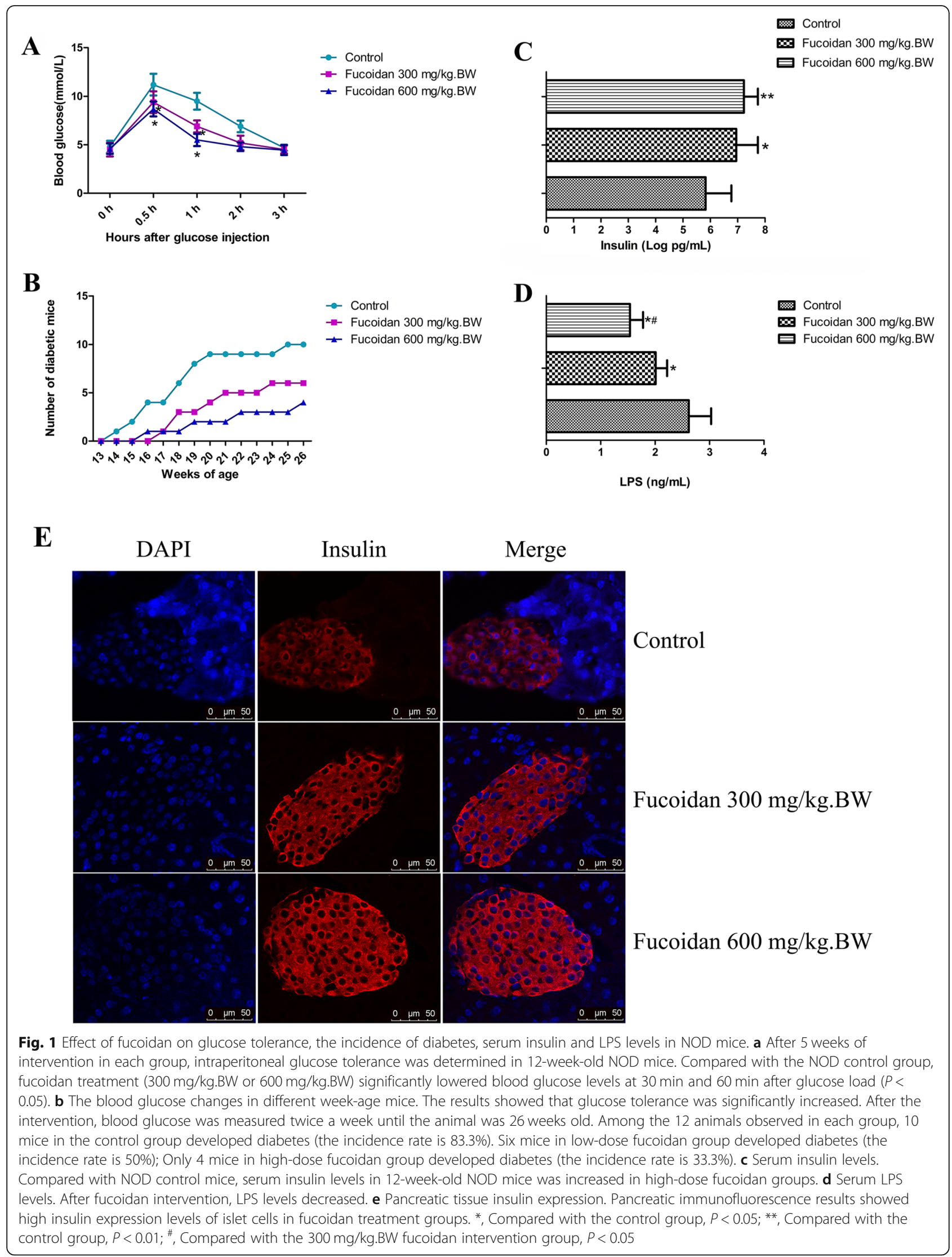




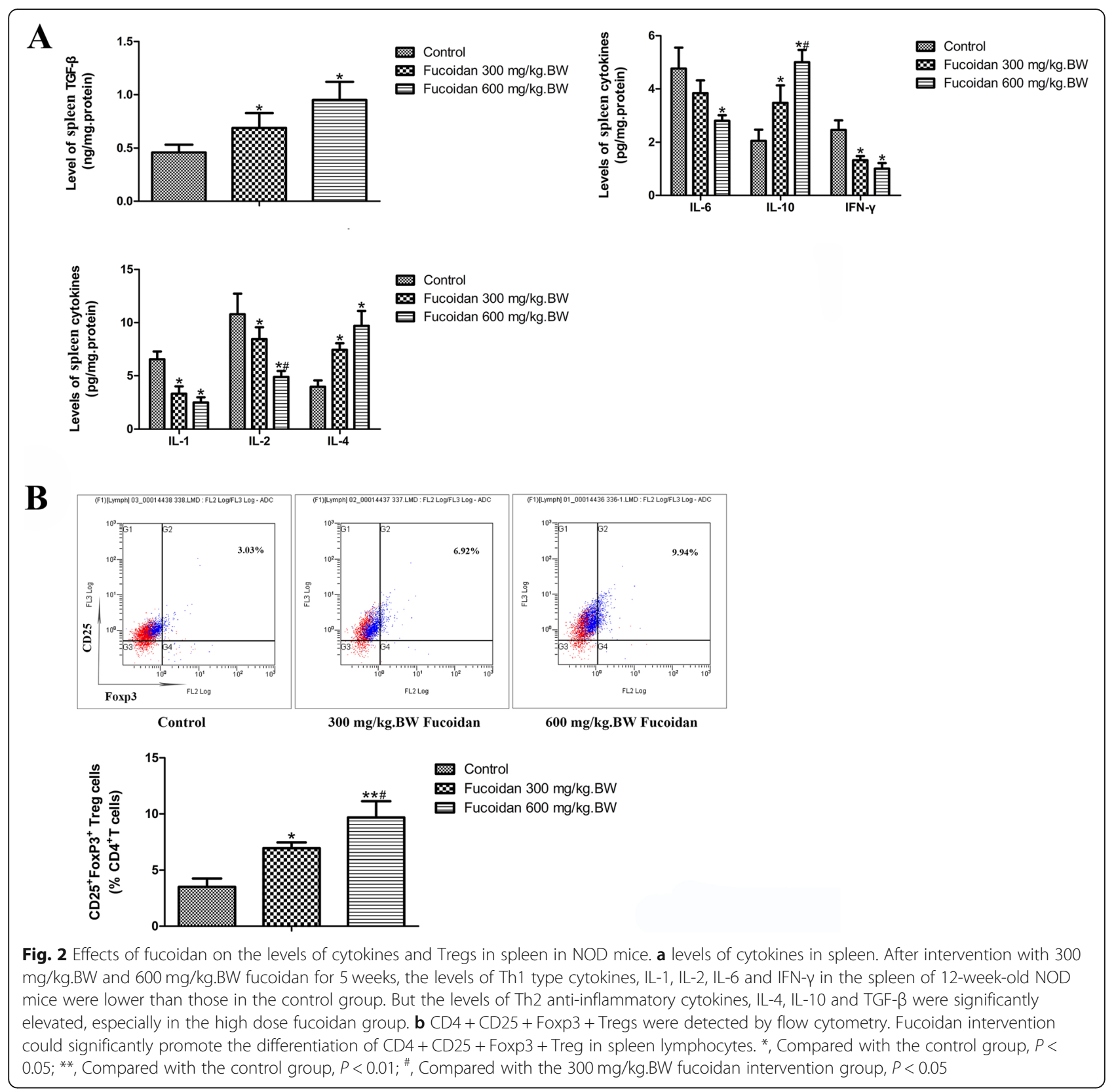

were decreased (Fig. 1d). Pancreatic immunofluorescence results showed that high insulin expression levels of islet cells in fucoidan treatment groups (Fig. 1e).

\section{Effect of fucoidan on the levels of inflammation in NOD mice}

As shown in Fig. 2a, after intervention with $300 \mathrm{mg}$ / $\mathrm{kg} . \mathrm{BW}$ and $600 \mathrm{mg} / \mathrm{kg} . \mathrm{BW}$ fucoidan for 5 weeks, the levels of Th1 type cytokines, IL-1, IL-2, IL- 6 and IFN- $\gamma$ in the spleen of 12-week-old NOD mice were lower than those in the control group. But the levels of Th2 antiinflammatory cytokines, IL-4, IL-10 and TGF- $\beta$ were significantly elevated, especially in the high dose fucoidan group. It showed that fucoidan could down-regulate Th1 cell-mediated autoimmune response, and induce Th2 cells to produce immunosuppressive cytokines.

The proportion of CD25+ Foxp3+ Tregs in spleen CD4+ T cells of 12-week-old NOD mice was determined by flow cytometry. As shown in Fig. 2b, CD $4+\mathrm{CD} 25+$ Foxp3+ Tregs in the control group was less differentiated, but the fucoidan intervention could significantly promote the differentiation of CD4+CD25+Foxp3 + Treg in spleen lymphocytes $(P<0.05)$. It shown that fucoidan intervention has the effect of inducing immune tolerance. Moreover, compared with the control group, fucoidan intervention up-regulated spleen Foxp3 levels (Fig. 3a, $P<$ 


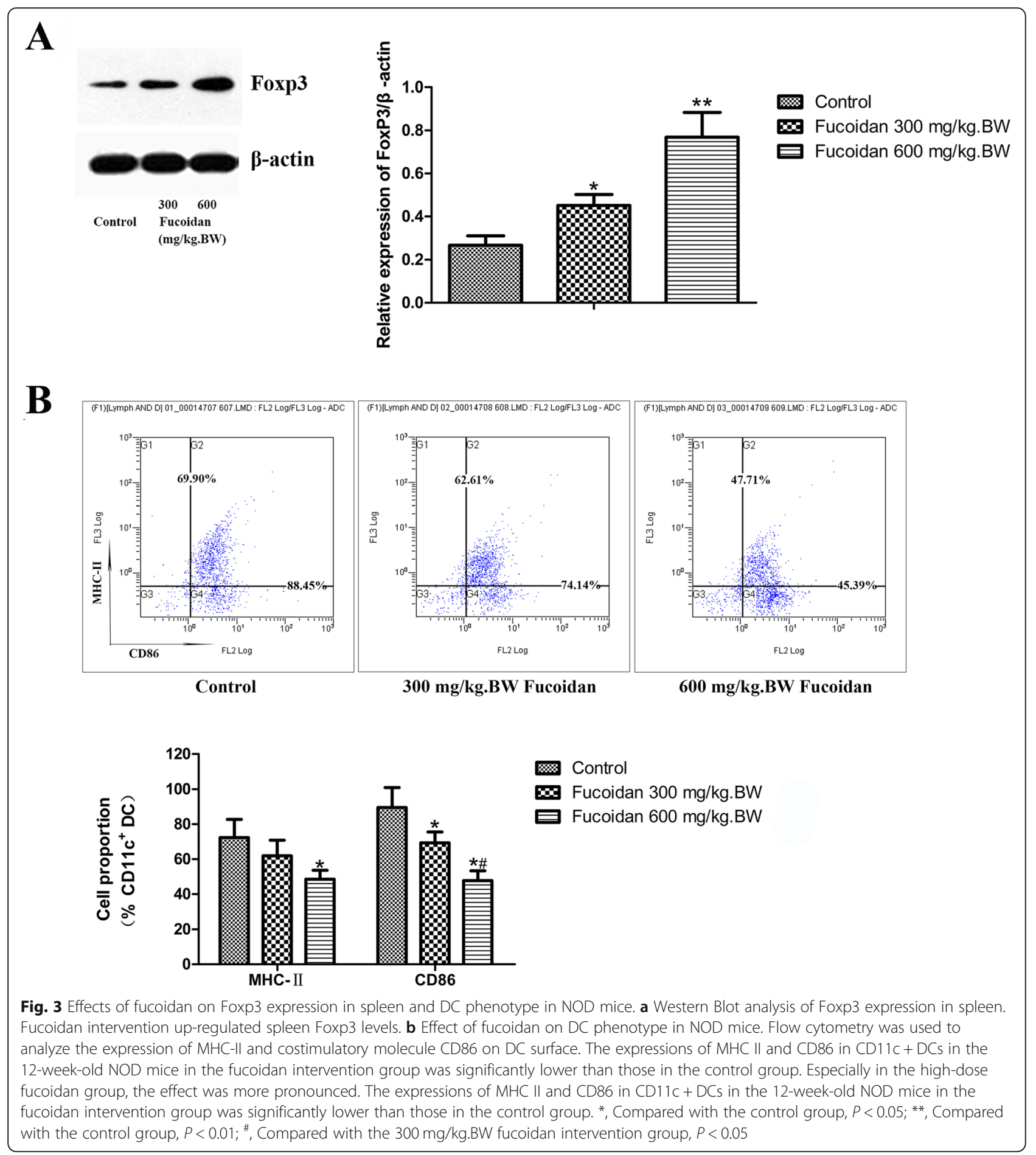

$0.01)$. The above results suggest that fucoidan could induce the differentiation of CD4+ CD25+ Foxp3+ T cells in vivo to promote the formation of immune tolerance.

Flow cytometry was also used to analyze the expression of MHC-II and costimulatory molecule CD86 on DC surface. CD11c is a DC landmark marker. The results showed that the expressions of MHC II and CD86 in CD11c + DCs in the 12-week-old NOD mice in the fucoidan intervention group was significantly lower than those in the control group. Especially in the highdose fucoidan group, the effect was more pronounced (Fig. 3b). It suggested that fucoidan could inhibit the 

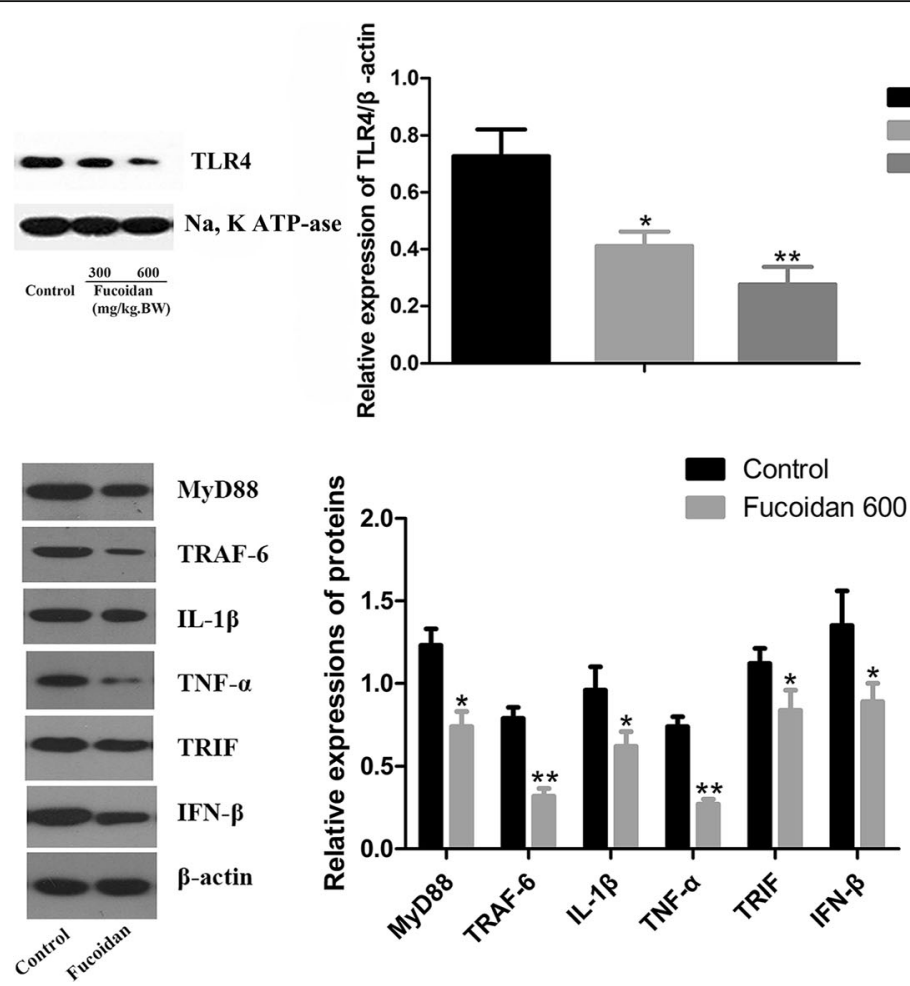

Control

Fucoidan $300 \mathrm{mg} / \mathrm{kg}$.BW

Fucoidan $600 \mathrm{mg} / \mathrm{kg} . \mathrm{BW}$
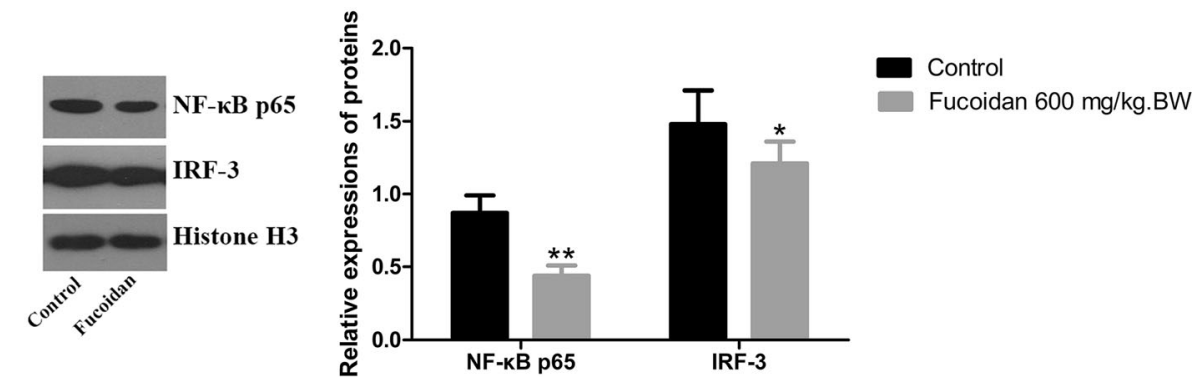

Fig. 4 Effect of fucoidan on down-regulation of MyD88-dependent and independent signaling pathways in pancreatic TLR4 in NOD mice. Western results showed that the expressions of MyD88, NF-KB p65 and IL-1 $\beta$ in pancreatic tissue were significantly down-regulated after 600 mg/ kg.BW fucoidan intervention. In addition, after $600 \mathrm{mg} / \mathrm{kg}$.BW fucoidan intervention, the expressions of TRIF, IRF-3 and IFN-Bin pancreatic tissue were significantly lower than those of the control group. ${ }^{*}$, Compared with the control group, $P<0.05 ;{ }^{*}$, Compared with the control group, $P<0.01$

expression of MHC II and CD86 on DC surface, maintain the immature state of DC, and induce immune tolerance in NOD mice.

\section{Effect of fucoidan on TLR4 pathway in pancreas of NOD mice}

To clarify the molecular mechanism by which fucoidan exerts a protective effect on T1DM, we used Western blot to determine the expression of TLR4 protein in pancreatic tissue. The results showed that fucoidan treatment could significantly down-regulate the expression of TLR4 protein.

To determine whether these two TLR4 downstream signaling pathways--- MyD88 dependent pathway and TRIF dependent pathway were involved in the protective effect of fucoidan on T1DM, we further examined the expression level of TLR4 downstream signaling molecules in pancreatic tissue of NOD mice after fucoidan intervention. Western results showed that the expressions of MyD88, NF-kB p65 and IL- $1 \beta$ in pancreatic tissue were significantly down-regulated after $600 \mathrm{mg} / \mathrm{kg}$.BW fucoidan intervention (Fig. 4). In addition, after $600 \mathrm{mg} / \mathrm{kg}$.BW fucoidan intervention the expressions of TRIF, IRF- 3 and IFN- $\beta$--. the key molecules of TRIF-dependent signaling pathway in pancreatic tissue, were significantly lower than those of the control group $(P<0.05 ; P<0.01)$. Immunofluorescence assay also showed reduced nuclear localization of NF-kB p65 and IRF-3 in fucoidan treatment group (Fig. 5). The data showed that fucoidan downregulated TLR4- 


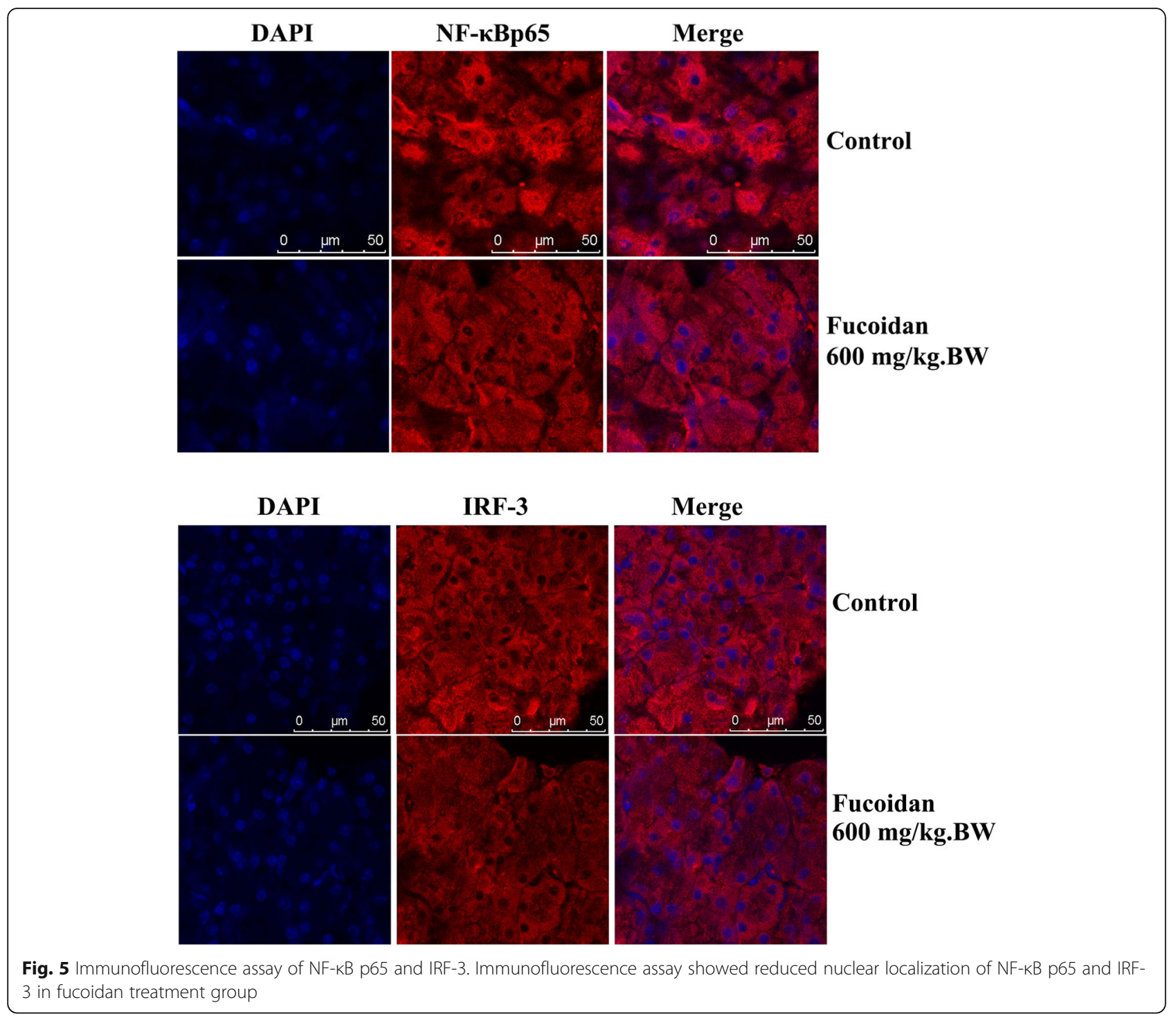

mediated MyD88-dependent signaling pathway and TLR4-mediated TRIF-dependent signaling pathway.

\section{Effect of fucoidan on intestinal flora of NOD mice}

We used Illumina Miseq high-throughput sequencing technology to sequence the $16 \mathrm{~S}$ rDNAV3-V4 region of the gut flora of NOD mice. The OTU abundances of each species was shown in Additional file 1. The alpha diversity index of the gut flora in NOD mice was shown in Fig. 6. There was no significant difference in the Chao1 index, observed_species index, Shannon index and Simpson index between the NOD control group and the $600 \mathrm{mg} / \mathrm{kg}$. BW fucoidan intervention group. This indicated that the difference in gut flora diversity between the two groups was not obvious.

In the Venn, the number of OTUs hold in common in the NOD control group and the $600 \mathrm{mg} / \mathrm{kg}$.BW fucoidan intervention group was 351 . The number of unique OTUs is 57 and 75 respectively (Fig. 6a). According to PCA analysis, there was a difference in microbial composition between the two groups (Fig. 6b). Based on weighted Unifrac clustering beta diversity analysis (Anosim), the results showed that the composition of the gut flora in the two groups was significantly different $(R=0.369, P=$ 0.001). At the OTU level, there was a significant difference in the gut flora structure between the control group and the fucoidan intervention group (Fig. $6 \mathrm{c}$ and d).

Cluster analysis showed that the composition of the gut flora in control group and the $600 \mathrm{mg} / \mathrm{kg}$.BW fucoidan intervention group was significantly different. The most dominant phyla in the two groups were Bacteroidetes and Firmicutes. The abundance of Bacteroides in the fucoidan intervention group was $51.37 \%$ and significantly lower than that in the NOD control group (63.97\%). In addition, the abundance of Verrucomicrobia was increased in fucoidan intervention group (8.41\%), but only $0.18 \%$ in the 
A
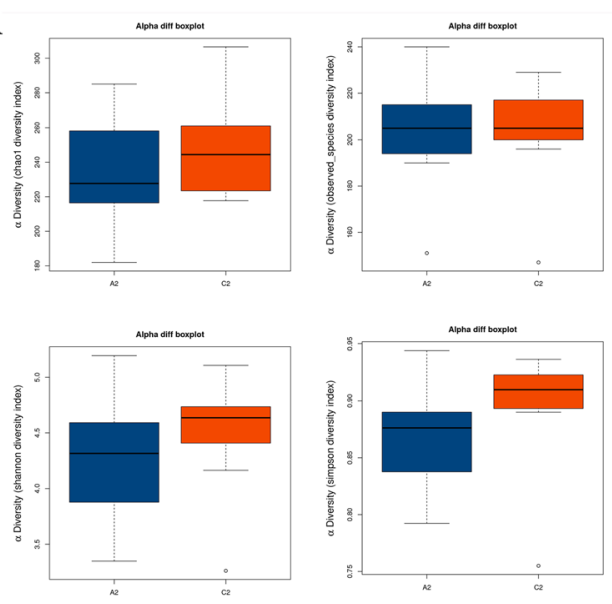

C
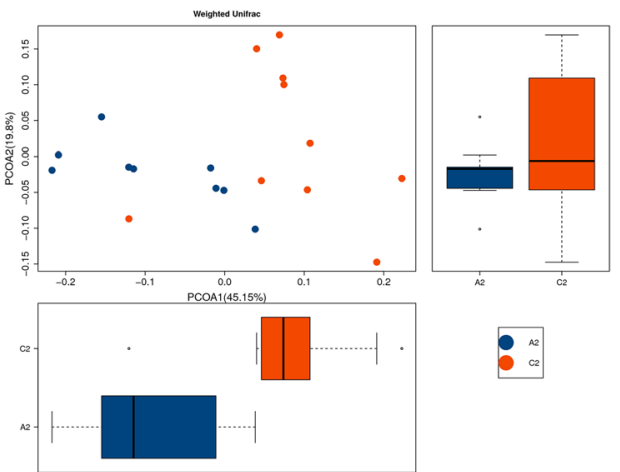

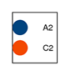

E

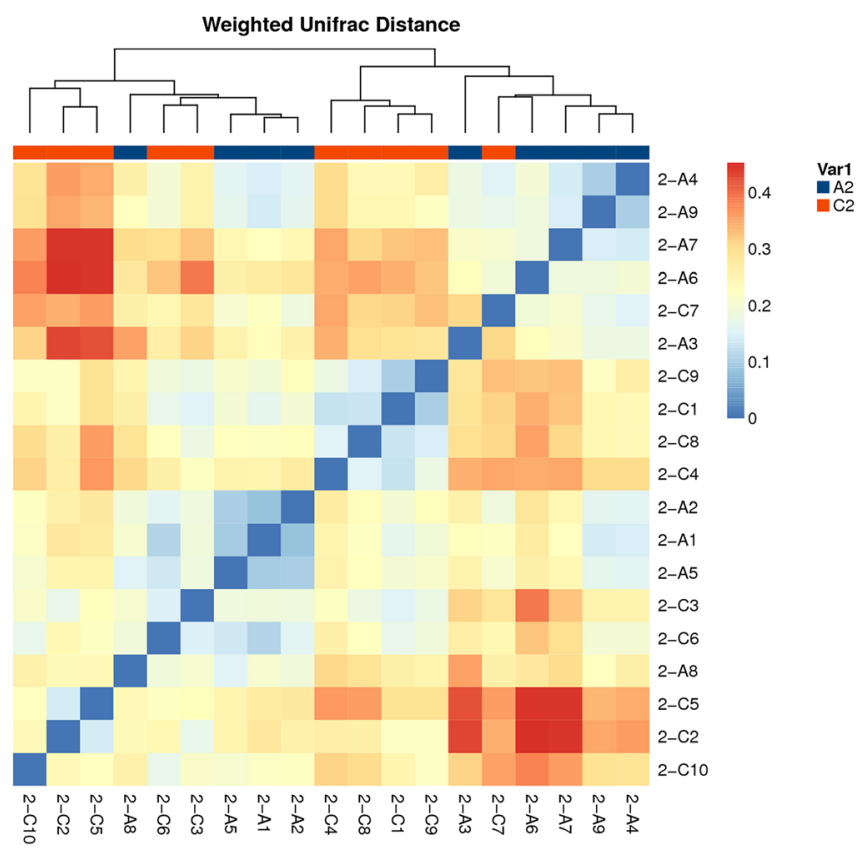

B

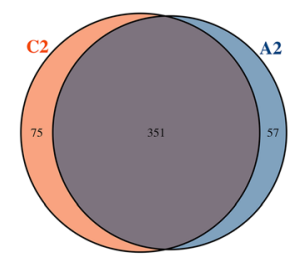

D

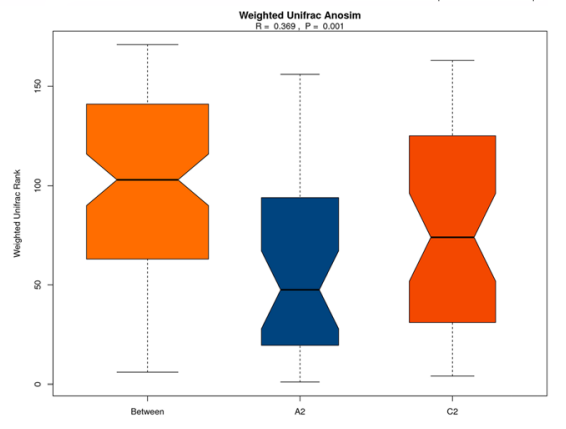

Fig. 6 (See legend on next page.) 


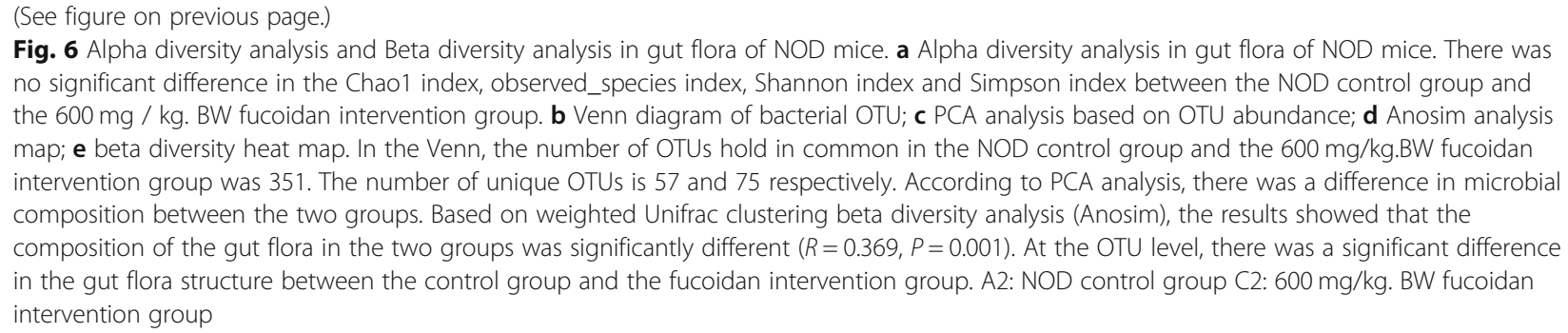

control group (Fig. 7a). At the family level, compared with the NOD control group, the abundances of Bacteroidaceae and Prevotellaceae were 22.6 and $4.00 \%$, respectively, and declined significantly after fucoidan intervention. But the abundance of Lactobacillaceae rose to $22.80 \%$, compared with $16.00 \%$ in the control group (Fig. 7b).

The results of the genus analysis indicated that the genus distribution of the gut flora of the two groups changed significantly. Bacteroides was the most dominant genus (46.84\%) in the NOD control group, however, the abundance of Bacteroides in the fucoidan intervention group was downregulated $(32.09 \%)$, and Lactobacillus became the dominant genus $(32.82 \%)$. It was worth mentioning that the apparent enrichment of Akkermansia occurred in the fucoidan intervention group, reaching to $12.69 \%$, and the control group was only $0.37 \%$. Other than that, the fucoidan intervention also increased the abundance of Clostridium XIVa and Anaerofustis, while the abundance of Alloprevotella, Enterorhabdus, and Mucispirillum was reduced (Fig. 7c).

\section{Spearman correlation analysis between genus species and serological indicators}

Spearman correlation analysis between genus species and serological indicators was shown in Fig. 8. The abundance of Lactobacillus was negatively correlated with the LPS and IFN- $\gamma$. The abundances of Akkermansia and Anaerofustis were negatively correlated with blood glucose of GTT $(1 \mathrm{~h})$ and IL-1, and positively correlated with the level of IL-10. In addition, the blood glucose of GTT (1 h) was positively correlated with the abundances of Enterorhabdus, and Mucispirillum. The abundances of Alloprevotella was positively correlated with the level of IL-IL-1, and negatively correlated with IL-10. The results indicated that fucoidan may reduce the level of inflammation and improve the glucose tolerance by regulating gut flora.

\section{Discussion}

In this study, we found that treatment with fucoidan for 5 weeks significantly increased insulin levels, improved the glucose tolerance, delayed the onset and decreased the development of diabetes by 26 weeks of age in NOD mice. Fucoidan reduced the levels of strong Th1 proinflammatory cytokines, but induced Th2-biased cytokine response, the generation of CD4+CD25+ Foxp3+ Tregs in spleen and Foxp3 expression in pancreas. And fucoidan-treated DCs were characterized as low expression of MHC class II and CD86 molecules.

T1DM is an autoimmune disease in which the absence of autoimmune tolerance causes specific damage to beta cells of the pancreas. Th1-mediated autoimmune disease is involved in T1DM [31, 32]. The relationship between T1DM and high levels of inflammatory cytokines such a TNF- , interferon- (IFN-) and IL-1 $\beta$ has been widely recognized. Increasing Th2-type cytokines (such as IL-10, TGF- $\beta$ ), and at the same time, reducing the production of Th1 type cytokines (such as IL-2, IFN- $\gamma$ ) are ideal means to prevent and control T1DM. CD4+CD25+Foxp3+ Treg cells control immune responses and maintain immunological tolerance [33]. These cells regulate cytokine production (IL-10 and TGF- $\beta$ ), modification of dendritic cell (DC) function (downregulation of co-receptors CD80/ 86), and cytokine deprivation (through sequestering of IL2 by CD25) [34]. Foxp3 is extremely important for the differentiation and function of Treg. Loss of Foxp3 expression produces inflammatory cells and is involved in the of T1DM [35]. Immune responses via several mechanisms including suppressive CD4 + CD25 + Foxp3+ Treg has an immunomodulatory effect, can fight the development of autoimmune diabetes. Our data suggested that fucoidan could induce the differentiation of CD4 + CD25 + Foxp3 pathogenesis $+\mathrm{T}$ cells in vivo, inhibit the expression of MHC II and CD86 on DC surface, down-regulate Th1 cell-mediated autoimmune response, and induce Th2 cells to produce immunosuppressive cytokines, that resulted in immune tolerance in NOD mice.

In order to clarify the mechanism of immune tolerance mediated by fucoidan, we investigated the effect of fucoidan on TLR4 and its related pathway molecules. There are two signaling pathways downstream of the TLR4 signaling pathway, MyD88 dependency and TRIF dependency (MyD88 independency) [36]. The TIR domain of TLR4 interacts with the adaptor protein MyD88. Once stimulated, TLR4 can bind to MyD88, activate TRAF-6, and cause the transcription factor NF- $\mathrm{kB}$ to activate into the nucleus, that leads to natural immune and inflammatory reactions including the production of the proinflammatory cytokines IL- $1 \beta$ and TNF- $\alpha$. TRIF is another molecule containing a TIR domain, that plays an 


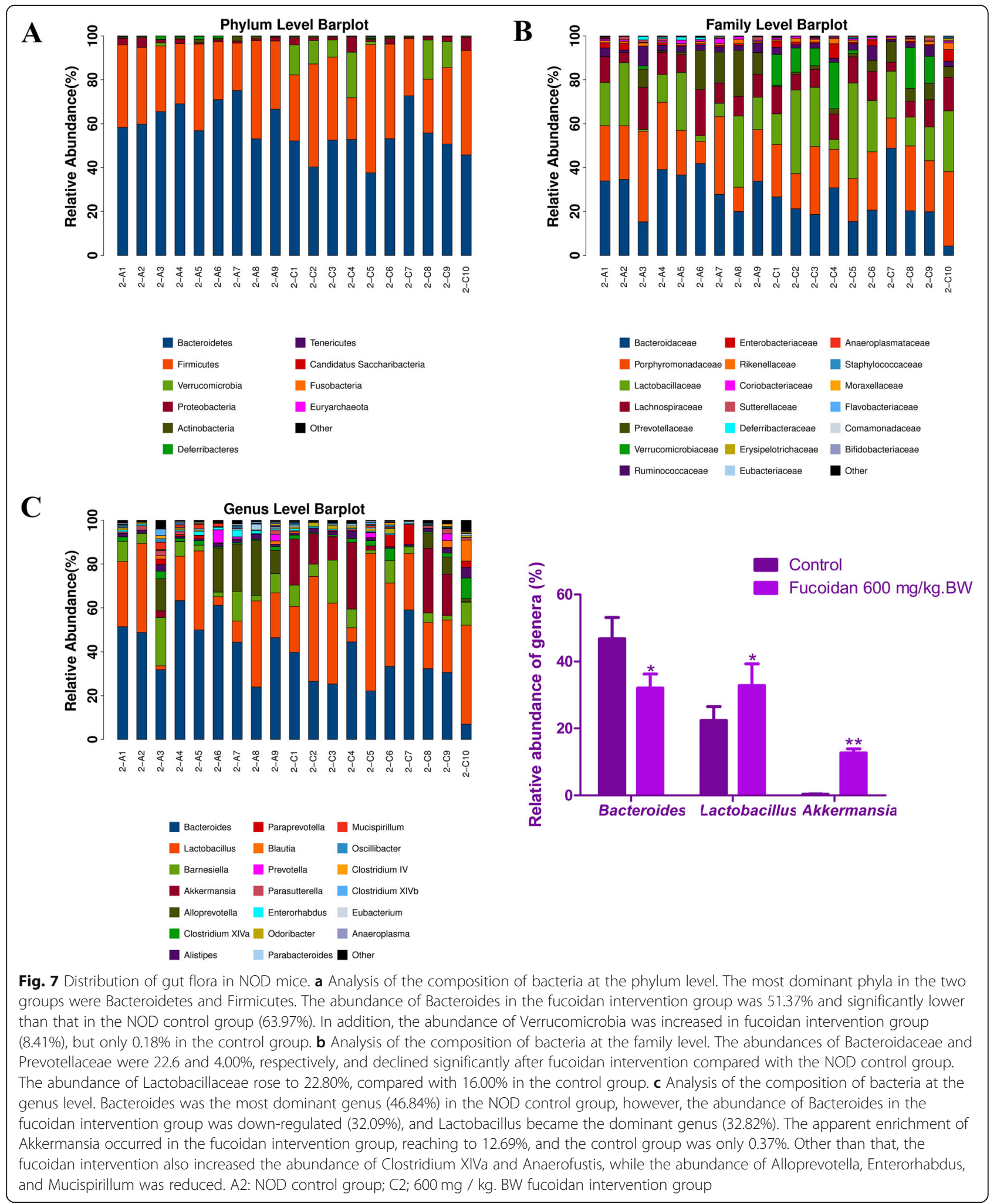

important role in the MyD88-independent signaling pathway downstream of TLR4 [37]. TRIF is essential in the process of stimulating IFN- $\beta$ production via IRF-3 (An essential DNA- binding transcriptional activator protein). Our results showed that fucoidan could down-regulated TLR4-mediated MyD88 dependent and TRIF-dependent signaling pathway. 


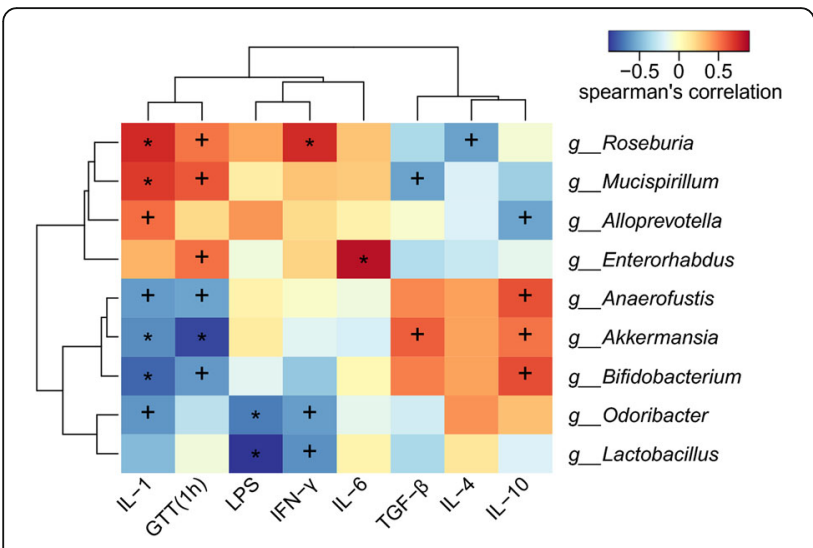

Fig. 8 Spearman correlation analysis between genus species and serological indicators. The abundance of Lactobacillus was negatively correlated with the LPS and IFN- $\gamma$. The abundances of Akkermansia and Anaerofustis were negatively correlated with blood glucose of GTT ( $1 \mathrm{~h}$ ) and IL-1, and positively correlated with the level of IL-10. In addition, the blood glucose of GTT (1 h) was positively correlated with the abundances of Enterorhabdus, and Mucispirillum. The abundances of Alloprevotella was positively correlated with the level of IL-IL-1, and negatively correlated with IL-10. The results indicated that fucoidan may reduce the level of inflammation and improve the glucose tolerance by regulating gut flora. $X$-axis, serological indicators; Y-axis, genus species. The depth of color visually shows the correlation between genus species and serological indicators. ${ }^{+}, P<0.05 ;{ }^{*}, P<0.01$

Moreover, gut flora plays a key role in regulating host metabolism, immunity and inflammation [38]. Intestinal flora imbalance is associated with various diseases, including obesity, diabetes, atherosclerosis, high blood pressure and so on. Gut microbial metabolites limit the frequency of autoimmune $\mathrm{T}$ cells and protect against type 1 diabetes [21]. In mice of the NOD strain, the researchers found that key features of disease correlated inversely with blood and fecal concentrations of the microbial metabolites, acetate and butyrate. Miani M, et al. [39] revealed that gut microbiota conditioned innate lymphoid cells (ILCs) induce the expression of mouse $\beta$ defensin 14 (mBD14) by pancreatic endocrine cells, preventing autoimmune diabetes in the NOD mice.

The data in this research showed that there were significant differences in the composition of gut flora between NOD control group and fucoidan treatment group. The abundance of Bacteroides phylum in the fucoidan intervention group was decreased, while the abundance of Verrucomicrobia phylum was increased. At the family level, the abundances of Bacteroidaceae and Prevotellaceae were declined significantly after fucoidan intervention. But the abundance of Lactobacillaceae rose to $22.80 \%$. It has reported that Bacteroides in the gut flora is a major producer of branched-chain amino acids, increased serum branched-chain amino acids lead to increased insulin resistance [40, 41]. Bacteroides was the most dominant genus in the NOD control group, however, in the fucoidan intervention group, the abundance of Bacteroides was down-regulated, and Lactobacillus became the dominant genus. It was worth mentioning that the apparent enrichment of Akkermansia occurred in the fucoidan intervention group. In addition, fucoidan also increased the abundances of Clostridium XlVa and Anaerofustis, and decreased the abundances of Alloprevotella, Enterorhabdus and Mucispirillum. Moreover, the abundance of Lactobacillus was negatively correlated with the LPS and IFN- $\gamma$. The abundances of Akkermansia and Anaerofustis were negatively correlated with blood glucose of GTT (1 h) and IL-1, and positively correlated with the level of IL10. Studies have shown that Lactobacillus can induce the secretion of IL-10, and prevention of T1DM by regulatory $\mathrm{T}$ cells [42]. Lactobacillus casei can alter the shape of dendritic cells, making DC more sensitive to IL-10, producing immune tolerance and delaying the development of T1DM [43]. Akkermansia is a significantly reduced flora of diabetic patients and pre-diabetes, feeding live AKK bacteria to high-fat diet mice can reverse metabolic disorders such as insulin resistance [44-46]. Clostridium species have been associated with the number and function of Treg cells in the colon of mice [47]. In this study, after fucoidan intervention Bacteroides was downregulated in NOD mice, but Lactobacillus and Akkermansia were obviously enriched. It indicated that fucoidan may reduce the level of inflammation, improve the glucose tolerance and delay the occurrence of T1DM by regulating gut flora.

In addition, Bacterial species that are protective against diabetes might display qualities through innate signaling molecules, such as LPS [48]. TLR4 is a receptor for LPS, and the pro-inflammatory activity of TLR4 is linked with pathological responses to endogenous ligands in autoimmune disorders [49]. After fucoidan intervention, LPS levels were decreased. It may be one of the mechanisms of fucoidan for down-regulating TLR4 pathway that fucoidan reduced the production of LPS by affecting the gut flora.

\section{Conclusions}

This study suggested that fucoidan could prevent the development of autoimmune diabetes in NOD mice via regulating $\mathrm{DC} /$ Treg induced immune tolerance, improving gut microecology, down-regulating TLR4 signaling pathway, and maintaining pancreatic internal environment by enhancing autophagy and inhibiting apoptosis of pancreatic cells.

\section{Supplementary information}

Supplementary information accompanies this paper at https://doi.org/10. 1186/s12986-019-0392-1.

Additional file 1. Raw sequence reads of each fecal flora species. The categories and abundance of the bacteria that were detected in the samples were listed in the file. 


\section{Abbreviations}

CE TAL: Chromogenic end-point Tachypleus amebocyte lysate; DC: Dendritic cells; EU: Endotoxin units; IFN: Interferon; IPGTT: Intraperitoneal glucose tolerance test; IRF: Interferon regulatory factor; LPS: Lipopolysaccharide; NOD: Non-obese diabetic; T1DM: Type 1 diabetes mellitus; TBS: Tris-buffered saline; TFEB: Transcription factor EB; TGF: transforming growth factor; TLRs: Toll-like receptors; Tregs: Regulatory T cells

\section{Acknowledgments}

We express our gratitude to all of the participants who consented to participate in this study.

\section{Authors' contributions}

MX was a major contributor in writing the manuscript. $\mathrm{HL}$ conceived and designed, supervised, and lead the study. YG, LH collected samples. XJ, YL contributed to discussion and revision of the manuscript. TS analyzed the data and wrote the manuscript. All authors read and approved the final manuscript.

\section{Funding}

This work was supported by the National Nature Science Foundation of China (No. 81573137, No. 81872605, No. 81502298), Key Research and Development plan of Shandong province (No. 2017GSF18167), Qingdao people's Livelihood Science and Technology Project (No. 18-6-1-70-nsh), Major Scientific \& Engineering Projects of Innovation in Shandong Province (2019JZZY010818), and Qingdao Post-doctoral Application Research Project (No. 2015165)

\section{Availability of data and materials}

All data generated or analysed during this study are included in this published article [and its Additional files].

\section{Ethics approval}

The experiments were carried out according to the National Institutes of Health Guide for Care and Use of Laboratory Animals (Publication No. 85-23, revised 1985). Animal care and the protocols were in accordance with the Animal Experiment Guidelines of Qingdao University of Medicine and ethical approval was obtained from Qingdao University of Medicine.

\section{Consent for publication}

Not applicable

\section{Competing interests}

The authors declare that they have no competing interests.

\section{Author details}

'Department of Biochemistry and Molecular Biology, Basic Medical College, Qingdao University of Medicine, 38 Dengzhou Road, Qingdao 266021, People's Republic of China. ${ }^{2}$ The Institute of Human Nutrition, Qingdao University of Medicine, Qingdao 266021, People's Republic of China. ${ }^{3}$ Department of Gynaecology, the Affiliated Hospital of Qingdao University, Qingdao 266021, People's Republic of China.

Received: 20 May 2019 Accepted: 6 September 2019 Published online: 16 December 2019

\section{References}

1. Malik FS, Taplin CE. Insulin therapy in children and adolescents with type 1 diabetes. Paediatr Drugs. 2014;16(2):141-50.

2. Mills KH. TLR-dependent T cell activation in autoimmunity. Nat Rev Immunol. 2011;11(12):807-22.

3. Li M, Song L, Gao X, Chang W, Qin X. Toll-like receptor 4 on islet $\beta$ cells senses expression changes in high-mobility group box 1 and contributes to the initiation of type 1 diabetes. Exp Mol Med. 2012;44(4):260-7.

4. Cejkova P, Nemeckova I, Broz J, Cerna M. TLR2 and TLR4 expression on CD14(++) and CD14(+) monocyte subtypes in adult-onset autoimmune diabetes. Biomed Pap Med Fac Univ Palacky Olomouc Czech Repub. 2016; 160(1):76-83.

5. Devaraj S, Dasu MR, Rockwood J, Winter W, Griffen SC, Jialal I. Increased tolllike receptor (TLR) 2 and TLR4 expression in monocytes from patients with type 1 diabetes: further evidence of a proinflammatory state. J Clin Endocrinol Metab. 2008:93(2):578-83.

6. Devaraj S, Dasu MR, Park SH, Jialal I. Increased levels of ligands of toll-like receptors 2 and 4 in type 1 diabetes. Diabetologia. 2009;52(8):1665-8.

7. Devaraj S, Jialal I, Yun JM, Bremer A. Demonstration of increased toll-like receptor 2 and toll-like receptor 4 expression in monocytes of type 1 diabetes mellitus patients with microvascular complications. Metabolism. 2011;60(2):256-9.

8. Devaraj S, Tobias P, Jialal I. Knockout of toll-like receptor-4 attenuates the pro-inflammatory state of diabetes. Cytokine. 2011;55(3):441-5.

9. Battaglia $\mathrm{M}$, Roncarolo MG. Immune intervention with T regulatory cells: past lessons and future perspectives for type 1 diabetes. Semin Immunol. 2011;23(3):182-94.

10. Green EA, Gorelik L, McGregor CM, Tran EH, Flavell RA. CD4+CD25+ T regulatory cells control anti-islet CD8+ T cells through TGF-beta-TGF-beta receptor interactions in type 1 diabetes. Proc Natl Acad Sci U S A. 2003; 100(19):10878-83.

11. Lindley S, Dayan CM, Bishop A, Roep BO, Peakman M, Tree TI. Defective suppressor function in CD4(+) CD25(+) T-cells from patients with type 1 diabetes. Diabetes. 2005:54(1):92-9.

12. Sgouroudis E, Piccirillo CA. Control of type 1 diabetes by CD4+Foxp3+ regulatory $T$ cells: lessons from mouse models and implications forhuman disease. Diabetes Metab Res Rev. 2009;25(3):208-18.

13. Marek-Trzonkowska N, Myśliwiec M, Dobyszuk A, Grabowska M, Derkowska I, Juścińska J, Owczuk R, Szadkowska A, Witkowski P, Młynarski W, Jarosz-Chobot P, Bossowski A, Siebert J, Trzonkowski P. Therapy of type 1 diabetes with CD4(+) CD25(high)CD127-regulatory T cells prolongs survival of pancreatic islets - results of one year follow-up. Clin Immunol. 2014;153(1):23-30.

14. Cheatem D, Ganesh BB, Gangi E, Vasu C, Prabhakar BS. Modulation of dendritic cells using granulocyte-macrophage colony-stimulating factor (GM-CSF) delays type 1 diabetes by enhancing CD4+CD25+ regulatory $T$ cell function. Clin Immunol. 2009;131(2):260-70.

15. Huang Y, Parker M, Xia C, Peng R, Wasserfall C, Clarke T, Wu L, Chowdhry T, Campbell-Thompson M, Williams J, Clare-Salzler M, Atkinson MA, Womer KL. Rabbit polyclonal mouse antithymocyte globulin administration alters dendritic cell profile and function in NOD mice to suppress diabetogenic responses. J Immunol. 2009;182(8):4608-15.

16. Li B, Selmi C, Tang R, Gershwin ME, Ma X. The microbiome and autoimmunity: a paradigm from the gut-liver axis. Cell Mol Immunol. 2018; 15(6):595-609.

17. Gülden E, Wong FS, Wen L. The gut microbiota and type 1 diabetes. Clin Immunol. 2015;159(2):143-53.

18. Knip $M$, Siljander $H$. The role of the intestinal microbiota in type 1 diabetes mellitus. Nat Rev Endocrinol. 2016;12(3):154-67.

19. Sargent J. Autoimmunity T1DM and the gut microbiome. Nat Rev Endocrinol. 2015;11(4):193.

20. Peng J, Hu Y, Wong FS, Wen L. The gut microbiome in the NOD mouse. Methods Mol Biol. 2016;1433:169-77.

21. Mariño E, Richards JL, McLeod KH, Stanley D, Yap YA, Knight J, McKenzie C, Kranich J, Oliveira AC, Rossello FJ, Krishnamurthy B, Nefzger CM, Macia L, Thorburn A, Baxter AG, Morahan G, Wong LH, Polo JM, Moore RJ, Lockett TJ, Clarke JM, Topping DL, Harrison LC, Mackay CR. Gut microbial metabolites limit the frequency of autoimmune T cells and protect against type 1 diabetes. Nat Immunol. 2017;18(5):552-62.

22. Kan J, Hood M, Burns C, Scholten J, Chuang J, Tian F, Pan X, Du J, Gui M. A novel combination of wheat peptides and fucoidan attenuates ethanolinduced gastric mucosal damage through anti-oxidant, anti-inflammatory, and pro-survival mechanisms. Nutrients. 2017;9(9):978.

23. Yu HH, Chengchuan Ko E, Chang CL, Yuan KS, Wu ATH, Shan YS, Wu SY. Fucoidan inhibits radiation-induced pneumonitis and lung fibrosis by reducing inflammatory cytokine expression in lung tissues. Mar Drugs. 2018;16(10):392.

24. Wang Y, Nie M, Lu Y, Wang R, Li J, Yang B, Xia M, Zhang H, Li X. Fucoidan exerts protective effects against diabetic nephropathy related to spontaneous diabetes through the NF-KB signaling pathway in vivo and in vitro. Int J Mol Med. 2015;35(4):1067-73.

25. Xu Y, Zhang Q, Luo D, Wang J, Duan D. Low molecular weight fucoidan modulates P-selectin and alleviates diabetic nephropathy. Int J Biol Macromol. 2016;91:233-40

26. Shi H, Chang Y, Gao Y, Wang X, Chen X, Wang Y, Xue C, Tang Q. Dietary fucoidan of Acaudina molpadioides alters gut microbiota and mitigates intestinal mucosal injury induced by cyclophosphamide. Food Funct. 2017; 8(9):3383-93. 
27. Shang Q, Shan X, Cai C, Hao J, Li G, Yu G. Dietary fucoidan modulates the gut microbiota in mice by increasing the abundance of Lactobacillus and Ruminococcaceae. Food Funct. 2016;7(7):3224-32.

28. Xue $M$, Ji $X$, Liang $H$, Liu Y, Wang B, Sun L, Li W. The effect of fucoidan on intestinal flora and intestinal barrier function in rats with breast cancer. Food Funct. 2018;9(2):1214-23.

29. Black WAP, Dewar ET, Woodward FN. Manufacture of algalchemiccals. IV. Laboratory-scale isolation from brown marine algae. J Sci Food Agric. 1952;3:122-9.

30. Xue M, Liu Y, Lyu R, Ge N, Liu M, Ma Y, Liang H. Protective effect of aplysin on liver tissue and the gut microbiota in alcohol-fed rats. PLoS One. 2017; 12(6):e0178684.

31. Westwell-Roper CY, Ehses JA, Verchere CB. Resident macrophages mediate islet amyloid polypeptide-induced islet IL-1 $\beta$ production and $\beta$-cell dysfunction. Diabetes. 2014;63(5):1698-711.

32. Sánchez-Zamora Yl, Juarez-Avelar I, Vazquez-Mendoza A, Hiriart M, Rodriguez-Sosa M. Altered macrophage and dendritic cell response in Mif -/- mice reveals a role of Mif for inflammatory-Th1 response in type 1 diabetes. J Diabetes Res. 2016;2016:7053963.

33. Vignali DA, Collison LW, Workman CJ. How regulatory T cells work. Nat Rev Immunol. 2008;8(7):523-32.

34. Campbell DJ, Koch MA. Phenotypical and functional specialization of FOXP3+ regulatory T cells. Nat Rev Immunol. 2011;11(2):119-30.

35. Sakaguchi S. Naturally arising Foxp3-expressing CD25+CD4+ regulatory $T$ cells in immunological tolerance to self and non-self. Nat Immunol. 2005; 6(4):345-52.

36. Iwasaki A, Medzhitov R. Toll-like receptor control of the adaptive immune responses. Nat Immunol. 2004;5(10):987-95.

37. Sabroe I, Parker LC, Dower SK, Whyte MK. The role of TLR activation in inflammation. J Pathol. 2008;214(2):126-35.

38. Gao J, Xu K, Liu H, Liu G, Bai M, Peng C, Li T, Yin Y. Impact of the gut microbiota on intestinal immunity mediated by tryptophan metabolism. Front Cell Infect Microbiol. 2018;8:13.

39. Miani M, Le Naour J, Waeckel-Enée E, Verma SC, Straube M, Emond P, Ryffel $B$, van Endert $P$, Sokol H, Diana J. Gut microbiota-stimulated innate lymphoid cells support $\beta$-defensin 14 expression in pancreatic endocrine cells, preventing autoimmune diabetes. Cell Metab. 2018;28(4):557-572.e6.

40. Pedersen HK, Gudmundsdottir V, Nielsen HB, Hyotylainen T, Nielsen T, Jensen BA, Forslund K, Hildebrand F, Prifti E, Falony G, Le Chatelier E, Levenez F, Doré J, Mattila I, Plichta DR, Pöhö P, Hellgren LI, Arumugam M, Sunagawa S, Vieira-Silva S, Jørgensen T, Holm JB, Trošt K, Consortium MHIT, Kristiansen K, Brix S, Raes J, Wang J, Hansen T, Bork P, Brunak S, Oresic M, Ehrlich SD, Pedersen O. Human gut microbes impact host serum metabolome and insulin sensitivity. Nature. 2016;535(7612):376-81.

41. Gar C, Rottenkolber M, Prehn C, Adamski J, Seissler J, Lechner A. Serum and plasma amino acids as markers of prediabetes, insulin resistance, and incident diabetes. Crit Rev Clin Lab Sci. 2018;55(1):21-32.

42. Manirarora JN, Parnell SA, Hu YH, Kosiewicz MM, Alard P. NOD dendritic cells stimulated with lactobacilli preferentially produce IL-10 versus IL-12 and decrease diabetes incidence. Clin Dev Immunol. 2011:2011:630187.

43. Takiishi T, Cook DP, Korf H, Sebastiani G, Mancarella F, Cunha JP, Wasserfall C, Casares N, Lasarte JJ, Steidler L, Rottiers P, Dotta F, Gysemans C, Mathieu C. Reversal of diabetes in NOD mice by clinical-grade proinsulin and IL-10secreting lactococcus lactis in combination with low-dose anti-CD3 depends on the induction of Foxp3-positive T cells. Diabetes. 2017;66(2):448-59.

44. Candela M, Biagi E, Soverini M, Consolandi C, Quercia S, Severgnini M, Peano C, Turroni S, Rampelli S, Pozzilli P, Pianesi M, Fallucca F, Brigidi P. Modulation of gut microbiota dysbioses in type 2 diabetic patients by macrobiotic Ma-Pi 2 diet. Br J Nutr. 2016;116(1):80-93.

45. Anhê FF, Roy D, Pilon G, Dudonné S, Matamoros S, Varin TV, Garofalo C, Moine Q, Desjardins Y, Levy E, Marette A. A polyphenol-rich cranberry extract protects from diet-induced obesity, insulin resistance and intestinal inflammation in association with increased Akkermansia spp. population in the gut microbiota of mice. Gut. 2015;64(6):872-83.

46. Schneeberger M, Everard A, Gómez-Valadés AG, Matamoros S, Ramírez S, Delzenne NM, Gomis R, Claret M, Cani PD. Akkermansia muciniphila inversely correlates with the onset of inflammation, altered adipose tissue metabolism and metabolic disorders during obesity in mice. Sci Rep. 2015;5:16643.

47. Atarashi K, Tanoue T, Oshima K, Suda W, Nagano Y, Nishikawa H, Fukuda S, Saito T, Narushima S, Hase K, Kim S, Fritz JV, Wilmes P, Ueha S, Matsushima K, Ohno H, Olle B, Sakaguchi S, Taniguchi T, Morita H, Hattori M, Honda K.
Treg induction by a rationally selected mixture of clostridia strains from the human microbiota. Nature. 2013;500(7461):232-6.

48. Vatanen T, Kostic AD, d'Hennezel E, Siljander H, Franzosa EA, Yassour M, Kolde R, Vlamakis H, Arthur TD, Hämäläinen AM, Peet A, Tillmann V, Uibo R, Mokurov S, Dorshakova N, llonen J, Virtanen SM, Szabo SJ, Porter JA, Lähdesmäki H, Huttenhower C, Gevers D, Cullen TW, Knip M, DIABIMMUNE Study Group, Xavier RJ. Variation in microbiome LPS immunogenicity contributes to autoimmunity in humans. Cell. 2016;165(4):842-53.

49. Płóciennikowska A, Hromada-Judycka A, Borzęcka K, Kwiatkowska K. Cooperation of TLR4 and raft proteins in LPS-induced pro-inflammatory signaling. Cell Mol Life Sci. 2015;72(3):557-81.

\section{Publisher's Note}

Springer Nature remains neutral with regard to jurisdictional claims in published maps and institutional affiliations.
Ready to submit your research? Choose BMC and benefit from:

- fast, convenient online submission

- thorough peer review by experienced researchers in your field

- rapid publication on acceptance

- support for research data, including large and complex data types

- gold Open Access which fosters wider collaboration and increased citations

- maximum visibility for your research: over $100 \mathrm{M}$ website views per year

At $\mathrm{BMC}$, research is always in progress.

Learn more biomedcentral.com/submissions 